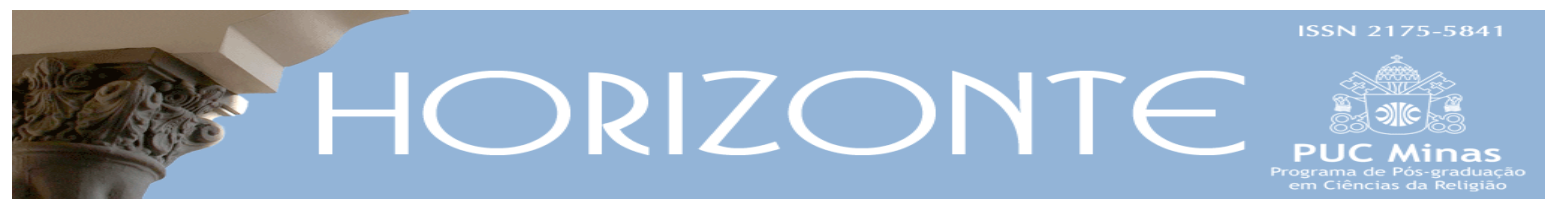

Dossiê: Fundamentalismos e Democracia - Artigo Original (c) $\underset{\mathrm{EY}}{(0)}$

\title{
Fundamentalismo à brasileira: perfil e enfoque do Protestantismo de Missão no Brasil
}

\author{
Brazilian-style fundamentalism: \\ Protestantism of Mission, its profile and focus on Brazil
}

Carlos Alberto Motta Cunha *

\begin{abstract}
Resumo
"Fundamentalismo" é um movimento ou uma corrente de pensamento, que prega obediência rigorosa e literal a um conjunto de princípios fundamentais. Pode estar presente na economia, na política, na educação e em outras instâncias da vida humana. É na religião que o fundamentalismo é mais conhecido e relacionado. Fundamentalismo religioso tem fases de expressão no decorrer da história possibilitando novas elaborações conceituais e estruturais. Nos últimos anos, o tema ressurge na América Latina quando governos fazem das ideias fundamentalistas a sua base. Há uma junção perigosa entre os fundamentalismos religioso e político. $\mathrm{O}$ objetivo desse artigo consiste em avaliar criticamente esta relação e os seus desdobramentos sociais. O texto se divide em: 1) distinção entre "conservadorismo" e "fundamentalismo"; 2) panorama sobre as fases de expressão do fundamentalismo cristão de matriz protestante; 3 ) a Bíblia como base do The Fundamentals: a Testimony to the Truth; 4) fundamentalismo à brasileira, a partir do protestantismo de missão e do pentecostalismo. Os aspectos propositivos são sugeridos no decorrer da reflexão e, principalmente, no último momento do texto como apontamentos para repensar a formação teológica de líderes religiosos no Brasil.
\end{abstract}

Palavras-chave: Fundamentalismo cristão. Protestantismo de missão. Pentecostalismo. Fanatismo religioso. Intolerância política.

\begin{abstract}
"Fundamentalism" is a movement or a current of thought, which preaches strict and literal obedience to a set of fundamental principles. It can be present in the economy, politics, education and other instances of human life. However, it is in religion that fundamentalism is best known and discussed. Throughout history, religious fundamentalism has gone through different phases of expression enabling new conceptual and structural analysis. In recent years, the theme has resurfaced in Latin America where some governments' policies are based on fundamentalist ideas. There is a dangerous connection between religious and political fundamentalisms. This article aims to critically evaluate this relationship and its social consequences. The text is divided into four parts: 1) distinction between "conservatism" and "fundamentalism"; 2) an overview of the phases of expression of Christian Protestant fundamentalismo; 3) the Bible as the basis of The Fundamentals: a Testimony to the Truth; 4) Brazilian-style fundamentalism from Protestantism of mission and Pentecostalism. The propositional aspects are suggested all along this reflection and, mainly in the final part, as notes to rethink the theological formation of religious leaders in Brazil.
\end{abstract}

Keywords: Fundamentalism. Protestantism of mission. Pentecostalism. Religious fanaticism. Political intolerance.

Artigo submetido em 30 de junho de 2020 e aprovado em 24 de dezembro de 2020.

* Doutor em Teologia pela FAJE. Professor da PUC Minas. País de origem: Brasil. E-mail: carlosamc04@gmail.com 


\section{Introdução}

“A Bíblia voltou ao palácio”, exclamou com euforia a senadora Jeanine Áñez logo após a renúncia do presidente Evo Morales, na Bolívia (DA REDAÇÃO, 2019). "Deus retorna ao governo", completou o colega Fernando Camacho. No Brasil, Jair Messias Bolsonaro fez campanha eleitoral usando o slogan: "E conhecereis a verdade, e a verdade vos libertará" (Jo 8,32) (UOL Eleições 2018). Já na condição de presidente, o Messias fala ao povo, ao lado da Bíblia, e reforça a sua condição de "escolhido": "Brasil acima de tudo, Deus acima de todos" ("BRASIL ACIMA DE TUDO” [...], 2018). Fatos assim se tornaram frequentes nos Estados Unidos e em alguns países da América Latina nos últimos anos. Além da Bolívia e do Brasil, Chile, Equador e Argentina, por exemplo, convivem também com o avanço do fundamentalismo religioso e político (PASSARINHO, 2019).

A temática do fundamentalismo está presente na atualidade de forma complexa e difusa. Não só restrita ao ambiente religioso, mas presente em outros âmbitos da vida com significados e atuações múltiplos. Nos séculos XX e XXI, testemunhamos um tipo de fundamentalismo que investe na política em nome da religião. A base de alguns governos está apoiada em ideias fundamentalistas. Isto tem implicações sociais graves. O fundamentalismo religioso e os aportes da ciência, por exemplo, vivem um conflito permanente gerando alienação, violência e morte. A tensão é decorrente do posicionamento científico que entra em conflito com as verdades dos Textos Sagrados (MOLTMANN, 1993, p. 142).

Tratar sobre o tema se justifica diante desse cenário. O nosso objetivo aqui é discernir as fases do fundamentalismo cristão, de matriz protestante, identificando aquilo que lhe é constitutivo até um fundamentalismo específico que chamamos de "fundamentalismo à brasileira", enraizado no protestantismo de missão. Para isto, utilizamos, como principal fonte, o verbete escrito por C.T. McIntire na Enciclopédia Histórico-Teológica da Igreja Cristã. A opção pelo texto de McIntire se justifica na constatação da aceitação da Enciclopédia pelos centros de formação 
teológica do protestantismo de missão no Brasil. ${ }^{1}$ Mesmo apresentando limitações sobre o tema do fundamentalismo cristão, a pesquisa realizada por McIntire favorece apontamentos introdutórios para reflexões embrionários sobre um fundamentalismo religioso presente em algumas igrejas evangélicas, principalmente ao colocar a Bíblia como primazia na elaboração dos Fundamentos. ${ }^{2}$

Levando em consideração as delimitações ao tratar sobre o fundamentalismo, a nossa exposição se dá em quatro momentos. O primeiro consiste em diferenciar conservadorismo do fundamentalismo. A linha é tênue entre os dois movimentos, mas o fanatismo marca a distinção do segundo sobre o primeiro. No segundo momento, tratamos sobre as fases de expressão do fundamentalismo cristão. É uma exposição em linhas gerais com o objetivo de mostrar como, no decorrer da história, o fundamentalismo vai passando por uma mudança conceitual e estrutural. O que permanece para além do tempo e a sua fundamentação teórica com base na Bíblia, este é o tema da terceira parte do nosso texto. Já o último momento, é sobre o fundamentalismo à brasileira, perfil e enfoque. São apontamentos sobre o fundamentalismo religioso no protestantismo de missão e no pentecostalismo e o seu impacto na política e sociedade brasileiras.

Juntar em um mesmo texto fundamentalismo e protestantismo no contexto brasileiro não é uma tarefa fácil. A complexidade dos temas exige delimitações. Algumas delas estão pelo texto, mas uma já se faz necessária. Utilizamos a categoria "protestantismo de missão" para falar sobre o pluriverso evangélico no Brasil que compreende algumas Igrejas históricas (protestantes) e algumas Igrejas pentecostais e neopentecostais (evangélicas). Com a "pentecostalização" ou renovação das Igrejas históricas já não permite mais a distinção precisa entre protestantes, como aqueles das Igrejas batistas, presbiterianas e metodistas; e

\footnotetext{
${ }^{1}$ Apesar de não se ter efetuado pesquisa de campo para fundamentar esta afirmação, a experiência do pesquisador como professor em vários institutos e seminários de teologia em Belo Horizonte e região metropolitana por mais de 25 anos. Além disso, o contato com colegas professores e seminaristas de centros de formação teológica entre evangelicais e pentecostais também respaldam o que a experiência como professor havia constatado. No entanto, apesar dessa constatação, a alegação ainda se constitui uma intuição a ser referendada ou não por uma pesquisa de campo adequada.

2 Para uma pesquisa mais ampla sobre o "fundamentalismo", sugerimos: (ALMOND; SIVAN; APPLEBY, 1991); (CARPENTER, 1993); (DOBSON; FALWELL; HINDSON, 1986); (HANKINS, 2008); (MARSDEN, 1980; 1991); (MARTIN, 1996); (SILVA; BARBOSA, 2019).
} 
evangélicos, da Assembleia de Deus, do Evangelho Quadrangular, da Deus é Amor e outras. Protestantismo de missão e pentecostalismo quase que se fundem no Brasil.

O texto que se segue é fruto de reflexão que supera o fundamentalismo como mero objeto de pesquisa. Há uma participação concreta na realidade que envolve tanto o protestantismo de missão quanto o pentecostalismo. A fala por trás do fundamentalismo à brasileira abordado no texto é marcada pelo espaço socioepistêmico do sujeito que se deixa ser interpelado pelas demandas do fundamentalismo cristão. Estar no lugar da fala pode impor limites sobre a reflexão, mas também pode oferecer contribuições efetivas sobre o tema.

\section{Do conservadorismo ao fundamentalismo}

Difícil precisar com certeza quando e onde surge pela primeira vez o termo "fundamentalista". Talvez em um jornal batista chamado "Watchman-Examiner", por Curtis Lee, em 1920, nos Estados Unidos. Ao mesmo tempo, percebemos que na década de vinte do século $\mathrm{XX}$, o termo já estava disseminado em todos os lugares como alguém ou um grupo defensor ativo dos fundamentos da fé cristã. Por exemplo, o batista John Roach Straton deu a seu jornal o nome "O Fundamentalista" assinalando a sua linha identitária (MCINTIRE, 1990, p.187). Já com mais precisão, verificamos que o termo "fundamentalista" surge como um movimento nos Estados Unidos, logo após a Primeira Guerra Mundial, com um objetivo claro: reafirmar o cristianismo protestante ortodoxo frente às pretensões científicas da modernidade. $\mathrm{O}$ fundamentalismo assume uma postura apologética, não para mostrar a relevância da fé cristã ao mundo, mas como defesa da fé contra um sistema ameaçador. A teologia liberal, a crítica bíblica alemã, o darwinismo e qualquer outro pensamento que ousa questionar os ensinos bíblicos são considerados danosos para o fundamentalista.

O fundamentalismo é uma "reação religiosa contra toda forma de modernidade" (MARTY, 2004, p.762). Ele faz oposição às crenças consideradas 
seculares, ao próprio cientificismo e às suas ramificações em todos os âmbitos da existência humana. No cristianismo, o fenômeno é constitutivo do protestantismo tradicionalista, mas, com o tempo, vai avançando para outras tradições do próprio cristianismo e também para outras religiões. Mais evidente nas três religiões monoteístas, curiosamente, também chamadas de "religiões do livro" - judaísmo, islamismo e cristianismo -, o fundamentalismo "é uma reação diante dos questionamentos do 'tradicional', perguntas provocadoras que 'desestabilizam' a própria tradição. Por isso, é uma regressão, resultando daí que se qualifica como integrismo33, conservadorismo, tradicionalismo, restauração" (ARENS, 2007, p.381).

Martin Marty assinala que os "diversos conservadorismos, ortodoxias e outros tradicionalismos não são necessariamente fundamentalismos" (MARTY, 2004, p.763). Quando, então, tais posicionamentos se tornam manifestações fundamentalistas? Amós $\mathrm{Oz}$ sugere que o fanatismo é o indício de que um conservador se tornou um fundamentalista. Fanáticos religiosos são acríticos, violentos nas palavras e nas ações. Eles acreditam cegamente nos preceitos de uma religião de modo exagerado chegando ao ponto de serem intolerantes. "O fanatismo é, com frequência, intimamente relacionado a uma atmosfera de desespero profundo. Num lugar em que as pessoas sintam que não há nada além de derrota, humilhação e indignidade, podem recorrer a várias formas de violência desesperada" (OZ, 2004, p.16-17).

A linha que separa um conservador de um fundamentalista é delicada. "Sentindo-se ameaçados pelas forças destrutivas da modernidade, apoderam-se com avidez do que pode ajudá-los a repelir a ameaça feita à sua fé e à sua identidade pessoal e social" (MARTY, 2004, p.763). O fundamentalista propaga as suas ideias de modo proselitista e pré-críticas. Fechado ao diálogo, não tolera ser questionado. Refugia-se na aparente segurança do passado com medo do novo, do

\footnotetext{
${ }^{3}$ Alguns cientistas da religião conceituam o fundamentalismo católico de "integrismo". Com esse termo, compreendem a tendência no catolicismo de afirmar a integridade da doutrina do magistério eclesiástico que deve ser mantida sem concessões. Há os que ainda falam em "integralismo" e "neointegralismo", que retoma o tradicionalismo do século XIX, numa outra situação histórica de rejeição do Concílio Vaticano Il em nome da afirmação absoluta da tradição eclesiástica (PACE; STEFANI, 1992, p. 144-156).
} 
diferente. Seus fundamentos são categóricos. Está presente na religião, mas também em outros âmbitos da vida. Para um conhecimento efetivo sobre o fundamentalismo cristão, de matriz protestante, é necessário discernir as suas fases de expressão através da história.

\section{Fundamentalismo cristão e suas fases de expressão segundo C.T. McIntire}

C.T. McIntire escreveu o verbete "Fundamentalismo" para a Enciclopédia Histórico-Teológica da Igreja Cristã, volume II. Nele, McIntire faz um panorama do movimento fundamentalista no decorrer da história em pelo menos quatro fases de expressão. A sua abordagem é importante, porque ajuda a entender o fundamentalismo religioso como um movimento dinâmico e complexo que vai para além de um conservadorismo no ambiente eclesiástico para um posicionamento militante nos espaços públicos. O discurso que no início estava basicamente recluso às Igrejas em oposição ao mundo avança para a esfera política refletindo sobre toda a sociedade.

A primeira fase de expressão é durante a década de 1920, nos Estados Unidos. De caráter apologético, o fundamentalismo travou uma batalha para expulsar das Igrejas protestantes aqueles considerados por elas como os "inimigos da fé”. Ao elaborar os Os Fundamentos (The Fundamentals), falaremos sobre eles mais adiante, uma série de doze volumes contendo doutrinas fundamentais da tradição protestante e refutação aos movimentos modernistas, o fundamentalismo elencou uma lista de inimigos:

O romanismo, o socialismo, a filosofia moderna, o ateísmo, o eddyismo, o mormonismo, o espiritismo e outros semelhantes, mas acima de tudo, a teologia liberal, que se baseava numa interpretação naturalista das doutrinas da fé, a alta crítica alemã e o darwinismo, que pareciam subverter a autoridade da Bíblia. (MCINTIRE, 1990, p. 187).

Ao listar os inimigos a serem combatidos, os vários autores, de denominações diferentes, deram ao The Fundamentals o caráter de Index incriminando os adversários dos ensinos cristãos cristalizados pelo tradicionalismo protestante. Com o tempo, a argumentação elaborada pelos articulistas dos 
Fundamentos foi afunilando até afirmar cinco pontos essências, considerados, em 1923, as doutrinas fundamentais do cristianismo na ótica protestante: "a inerrância das Escrituras, o nascimento virginal de Cristo, Sua expiação vicária e Sua ressureição e a historicidade dos milagres” (MCINTIRE, 1990, p. 187). Os fundamentalistas não consideram cristãos os modernistas liberais e nem as suas teologias. Não viam com bons olhos o diálogo entre a teologia cristã e o pensamento moderno. Uma relação profana e prejudicial para a fé e prática cristãs.

Um exemplo famoso dessa rejeição à modernidade foi o processo de John Scopes (1925) em Dayton, no estado do Tennessee, em que os fundamentalistas opunham-se ao ensino do evolucionismo darwinista nas escolas públicas. O caso repercutiu de tal maneira que se tornou ilegal ensinar qualquer ideia diferente do criacionismo bíblico nos estabelecimentos educacionais do estado. O "julgamento do macaco", como popularmente ficou conhecido acabou condenando o professor Scopes a pagar multa e acirrou ainda mais a controvérsia entre evolucionismo e criacionismo nos Estados Unidos (FIORI; NENEVÊ, 2011, p. 54).

A segunda fase de expressão mencionada por McIntire vai de 1920 até o início dos anos 40. Nesta fase, o fundamentalismo convive com a frustração de não conseguir expurgar do protestantismo as ideias modernistas. Durante a Grande Depressão ou Crise de 1929, o fundamentalismo mudou de sentido e significado. De sentido porque o seu embate já não era tanto para além das Igrejas protestantes, mas internamente, isto é, uma luta entre as próprias denominações. E de significado, "à medida que veio a ser aplicado a um só partido entre aqueles que acreditavam nos fundamentos tradicionais da fé" (MCINTIRE, 1990, p. 188).

Como se considera representante do cristianismo verdadeiro, o fundamentalismo sustenta a ideia de que a sua administração eclesiástica deve ser basear numa interpretação literal da Bíblia. O Texto Sagrado é o fundamento da fé e da prática organizacional, livre de qualquer pensamento liberal e modernista. Assim, elabora novas denominações, associações, movimentos eclesiásticos e centros de formação fechados nos preceitos do "verdadeiro cristianismo". McIntire enumera algumas dessas organizações: 


\begin{abstract}
Associação Geral das Igrejas Batistas Regulares (1932), a Igreja Presbiteriana dos Estados Unidos (1936), que mudou seu nome para Igreja Presbiteriana Ortodoxa, a Igreja Presbiteriana Bíblica (1938), a Associação Batista Conservadora dos Estados Unidos (1947), as Igrejas Fundamentalistas Independentes dos Estados Unidos (1930) e muitos outros grupos. Os fundamentalistas dominavam ainda a enorme Convenção Batista do Sul, a Igreja Presbiteriana no Sul e movimentos eclesiásticos batistas, incluindo a Associação Batista Norte-Americana. Em todas as partes dos Estados Unidos, os fundamentalistas fundavam novos ministérios de reavivamento, agências missionárias, seminários, institutos bíblicos, conferências bíblicas e jornais. (MCINTIRE, 1990, p. 188).
\end{abstract}

Com o surgimento desses novos ministérios, o fundamentalismo encontrou meios de difundir o seu ideal de "pureza cristã". A leitura literalista da Bíblia era amplamente defendida, ensinada e, sobretudo, tida como fundamento para trabalhos missionários e formação teológica. Agências missionárias, por meio de seminários e institutos bíblicos, formavam a cabeça e o coração de líderes cristãos dispostos a cruzar o mundo em nome do "Ide fazer discípulos de todas as nações" (Mt 28,19) da Grande Comissão dada por Jesus Cristo. Neste empreendimento evangelístico ficava o alerta para que fé cristã não fosse maculada por ideias liberais por parte de "irmãos" da mesma tradição.

A terceira fase vai de 1940 até 1970 . Neste período, os fundamentalistas se dividiram em dois grupos distintos. Um se apresentava como fundamentalista convicto, fiel à Bíblia e porta-voz do verdadeiro cristianismo. Outro, não concordava em ser chamado de "fundamentalista" a fim de se evitar associações com comportamentos de intolerância e alienação social. A novidade deste segundo grupo, ainda de linha conservadora, era a aproximação de diálogo com a modernidade, mesmo que para refutá-la. Presentes nas grandes denominações presbiterianas, batistas e metodistas, os "evangelicais", como ficaram conhecidos durante a década de 1940, tinham por objetivo unir Igrejas protestantes em torno de princípios doutrinários comuns. Já a partir de 1948, alguns poucos são chamados de "neoevagelicais" assinalando para um movimento interessado em proclamar as dimensões "sociais do evangelho, como a necessidade de defender a justiça aos oprimidos pela sociedade e de oferecer cuidado e alívio aos que sofrem fisicamente" (GREZ; GURETZKI; NORDLING, 2000, p.53). 
Nas décadas de 1950 e 1960, fundamentalistas, evangelicais e neoevangelicais, mesmo com características distintas, tinham muita coisa em comum:

[...] Aderiam a doutrinas tradicionais das Escrituras e de Cristo; [...] promoviam a evangelização, reavivamentos, missões e uma moralidade pessoal contra o fumo, a bebida, o teatro, o cinema e o jogo de baralho; [...] identificavam os valores norte-americanos com os valores cristãos; [...] acreditavam em criar redes organizacionais que os separassem do restante da sociedade. (MCINTIRE, 1990, p. 189).

Os fundamentalistas se consideravam mais "crentes" do que os evangelicais e os neoevangelicais. Acreditavam serem "mais fiéis ao cristianismo bíblico, mais militantes contra a apostasia nas Igrejas, contra o comunismo, contra os vícios pessoais, menos dispostos a conformar-se com a respeitabilidade social e intelectual” (MCINTIRE, 1990, p. 189). Esta superioridade era acolhida com orgulho e passada para os futuros líderes das Igrejas protestantes ortodoxas por meio de centros de formação, tais como a Universidade Bob Jones, o Instituto Bíblico Moody e o Seminário Teológico de Dallas e por evangelistas itinerantes e pregadores de rádios. $\mathrm{O}$ orgulho fundamentalista se manifestava também por posicionamentos radicais frente a líderes e instituições mais abertas ao diálogo com o mundo. É o caso do evangelista Billy Graham, o jornal Christianity Today, a Faculdade Wheaton e o Seminário Teológico Fuller (MCINTIRE, 1990, p.189-190).

A quarta fase de expressão do fundamentalismo citada por McIntire vai de 1970 a 1980. Um novo inimigo é identificado: o humanismo secular. Para o fundamentalista, os tentáculos do humanismo secular subvertem "escolas, universidades, o governo e, acima de tudo, as famílias" (MCINTIRE, 1999, p.190). Além dos já combatidos evolucionismo e liberalismo, as novas expressões da modernidade no âmbito da moral e da política devem ser condenadas. A saber: a imoralidade pessoal, a liberdade sexual, o socialismo e o comunismo. Deve ser rejeitado qualquer pensamento que fomente práticas imorais e anarquistas, contrárias à autoridade inerrante e infalível da Bíblia. 
Com a intensificação dos meios de comunicação, principalmente a televisão e a palavra impressa, a nova geração de fundamentalistas encontrou nestes meios um instrumento efetivo para a proclamação de uma teologia conservadora fundamentada na leitura literal dos textos bíblicos. Televangelistas e ativistas conservadores como Jerry Falwell e Pat Robertson e pregadores, palestrantes e escritores como Tim La Haye e Hal Lindsey são alguns exemplos de muitos outros fundamentalistas que nas décadas de 1970 e 80 disseminaram o conservadorismo evangélico militante. Com a globalização das mídias, a mensagem fundamentalista rompeu as fronteiras dos Estados Unidos e alcançou públicos mais amplos. No Brasil, por exemplo, através de redes de televisão internacionais, declaradamente cristãs, o pastor Jimmy Swaggart influenciou toda uma geração de evangélicos nos anos de 1980.

O fundamentalismo desta época teve acesso a novos recursos tecnológicos para a divulgação da fé e prática fundamentalistas. Os adversários também eram mais contundentes nas argumentações que colocavam sob suspeita a ideia do fundamentalista sobre a Bíblia. O que permaneceu inalterado e rompeu as décadas até chegar aos nossos dias, pode ser sintetizado do seguinte modo: 1. Os fundamentalistas se consideram o verdadeiro cristianismo baseado numa leitura literal da Bíblia; 2. Tal posicionamento provoca uma superioridade sobre os demais ramos do cristianismo e sobre outras religiões; 3. Por serem fiéis ao evangelho de Jesus Cristo, acreditam que a sua missão consiste em lutar contra os inimigos que subvertem o cristianismo; 4. Conclamam a uma moralidade de tradição com uma vida livre das tentações do mundo; 5. Missão e evangelização se fundem como um projeto das Igrejas para a cristianização de todo o mundo; 6. Expectativa de uma segunda vinda de Cristo à terra, com sinais apocalípticos para um reino milenar.

"Os maiores fundamentalismos encontram-se no Ocidente". Com os ataques terroristas do 11 de setembro de 2001 nos Estados Unidos, a temática fundamentalista retorna ao cenário sociopolítico no século XXI. Não mais tanto como oposição às crenças seculares, mas como busca por respostas às incertezas dos tempos atuais. "A investida sobre a política em nome da religião é aspecto 
central" do fundamentalismo de hoje. Não se "busca secularização do Cristianismo, mas recristianização do mundo ocidental”, da política e do Estado. Os adeptos do fundamentalismo exigem que o governo, nas suas várias instâncias, seja porta-voz da concepção bíblico-fundamentalista da vida (DREHER, 2008, p. 452-456).

\section{Os Fundamentos e a Bíblia}

O breve panorama que fizemos sobre as fases de expressão do fundamentalismo revela como o movimento, no decorrer da história, vai assumindo contornos distintos à medida que novos embates surgem. Ser fundamentalista hoje não é necessariamente o mesmo de 1920. As interpelações feitas à fé e à prática fundamentalista se intensificam cada vez mais com os avanços da tecnociência e a pluralidade do mundo atual. Os meios utilizados pelo fundamentalista para combater os avanços da ciência e da sociedade também são outros. Hoje, além dos convencionais meios de comunicação em massa, temos também a internet e as redes sociais, instrumentos utilizados para a propagação do chamando "neofundamentalismo".

Para Albert Nolan, uma das tendências que caracterizam o neofundamentalismo religioso, seja cristão, muçulmano ou judeu, é a dependência de uma autoridade que forneça verdades absolutas, de verdades que não podem ser postas em questão ou em dúvida (NOLAN, 2008, p.29). Desde 1920 aos tempos atuais, a Bíblia ocupa esse papel para os fundamentalistas. A sua inspiração verbal é fonte de apoio para a elaboração do documento basilar do fundamentalismo The Fundamentals: a Testimony to the Truth (Os Fundamentos: um Testemunho em favor da Verdade).

Os Fundamentos, uma série de doze volumes de artigos publicados em Chicago, EUA, entre 1910 e 1915, são conteúdos de fé, verdades absolutas e intocáveis baseados numa leitura inerrante e infalível da Bíblia. Com uma edição superior a três milhões de exemplares, Os Fundamentos reúnem textos sobre: 
A inspiração verbal, literal, da Bíblia; a afirmação da verdadeira divindade e do nascimento virginal de Jesus, seu sacrifício expiatório vicário, através do seu sangue derramado, e de sua ressurreição corporal; a segunda vinda de Cristo à terra, na época vista como iminente com sinais apocalípticos ou com o retorno para um reino milenar, intermediário; negativa de aceitação dos resultados da ciência moderna, quando não correspondiam ao que designavam de "fé bíblica"; exclusão do status de verdadeiro cristão de todos aqueles que não aceitavam esse fundamentalismo (DREHER, 2008, p. 453).

Os três milhões de exemplares dos textos foram distribuídos gratuitamente a ministros, missionários e obreiros protestantes em todas as partes do mundo. $\mathrm{O}$ financiamento para esta iniciativa contou com a caridade de "dois leigos cristãos", Lyman e Milton Stewart, "ricos capitalistas do petróleo na Califórnia, que doavam os dividendos de alguns de seus investimentos de ações”. Os autores eram, principalmente, das Igrejas presbiterianas, anglicanas e batistas, da Inglaterra, Escócia, Canadá e, sobretudo, dos Estados Unidos. Os oitenta e três artigos do The Fundamentals compreendem declarações apologéticas sobre Deus, a revelação, a encarnação, a ressurreição, o Espírito Santo e a inspiração. Outra parte trata sobre a defesa da Bíblia contra a alta crítica alemã. Há também partes sobre a crítica aos movimentos modernistas; ênfase dada à evangelização e às missões, e testemunhos (MCINTIRE, 1990, p. 191).

Não buscamos aqui um detalhamento do conteúdo dos artigos do The Fundamentals. O nosso objetivo é mostrar que a estrutura doutrinária do fundamentalismo está enraizada em uma concepção do “ditado verbal” da Bíblia, isto é, no processo de composição dos textos sagrados, Deus ditou palavra por palavra por meio do seu Espírito e, neste caminho, o autor humano é considerado mero copista que registrou, sem erros e limitação, a mensagem divina. Esta ideia persiste pelos anos e marca o posicionamento radical do fundamentalismo bíblico. A Bíblia é a palavra de Deus e a sua inspiração é verbal, plena e com autoridade final. Visto que tem Deus como seu autor, ela não pode ter erro algum. Conceitos como os da inerrânia e infalibilidade são consequências lógicas da inspiração divina. Teólogos fundamentalistas refletem este posicionamento: 
Deus não pode mentir $(\mathrm{Hb}$ 6,18); sua Palavra é a verdade (Jo 17,17). Por isso, seja qual for o assunto sobre o qual a Bíblia diga alguma coisa, ela só dirá a verdade. Não existem erros históricos nem científicos nos ensinos das Escrituras. Tudo quanto a Bíblia ensina vem de Deus e, por isso, não tem a mácula do erro (GEISLER; NIX, 1997, p. 24).

A Bíblia é um objeto de fé. Para James Barr, no fundamentalismo, "a Bíblia é mais do que a fonte da verdade para a sua religião", é o centro dela. "Ela é uma entidade verbalizada, 'inscriturada' [...] É o símbolo religioso supremo, tangível, articulado, que se pode possuir e é acessível ao ser humano na terra” (BARR, 1977, p. 36).

A visão de mundo fundamentalista está influenciada pela visão de mundo bíblica. Seu mundo e suas imagens correspondem ao mundo e às imagens dos textos sagrados. Bíblia, Revelação e Palavra de Deus são sinônimas no fundamentalismo. Nenhuma parte das Escrituras deixa de receber total autoridade doutrinária. Ela toda é divinamente inspirada e capaz de orientar o fiel em tudo o que for necessário. Toda Bíblia reivindica, portanto, total e completa autoridade. Privilegiando pequenos versículos bíblicos, o fundamentalismo recorre a textos fora do contexto para extrair significados que justifiquem a sua fé e prática. Por exemplo, o texto do profeta Isaías: "Vai, pois, escreve isso numa tabuinha perante ele" (Is 30,8). É compreendido como uma ordem de Deus para escrever a sua mensagem eterna. Ou o texto do apóstolo Paulo a Timóteo: "Toda a Escritura é inspirada por Deus" (2 Tm 3.16), é interpretado como se toda a Bíblia, Antigo e Novo Testamentos, é composta por textos inspirados por Deus palavra por palavra (CUNHA, 2016, p. 86-87).

Os Fundamentos têm como referência fundamental a Sagrada Escritura. A teologia que emerge daí recorre a ela para fundamentar aprioristicamente suas doutrinas. Rejeitando o instrumental crítico da exegese bíblica, busca a eisegese para fazer dizer a certos textos o que se quer que digam. Os autores fundamentalistas não admitem o processo redacional dos textos, a sua evolução, aprofundamento e adaptação. Não se admite a tradição como processo de interpretação e de atualização da vida. Passa-se diretamente de Deus ao texto e 
deste ao presente, como se tivesse sido escrito aqui e agora. Portanto, a leitura da Bíblia para hoje se torna anacrônica.

"O fundamentalismo não se baseia na Bíblia, mas em uma ideia a respeito dela e nas orientações do líder". E mais: "Nem todo fundamentalista é literalista. Há aqueles que fazem adaptações de passagens dos textos sagrados para legitimar doutrinas e práticas [...] Há interpretação literal e figuradamente", afirma Eduardo Arens (ARENS, 2007, p.383). Assim, por mais que digam que suas doutrinas e práticas sejam bíblicas, na verdade, são fundamentadas em uma ideia equivocada sobre a Bíblia e já superada pelas teologias progressistas. Não é de se admirar que seminários e escolas bíblicas fundamentalistas tenham tanta aversão pela hermenêutica bíblica e pelo exercício exegético.

A própria Bíblia já é um texto interpretado. Não há porque negar o trabalho da hermenêutica aplicada aos textos bíblicos. É uma incoerência. Ao fazer das ideias do mundo bíblico as suas próprias ideias, os fundamentalistas legitimam discursos e ações contrários ao bom-senso e o bem comum. Identificam-se com o Israel do Antigo Testamento, "os escolhidos de Deus", e se comportam de forma exclusivista, como donos da verdade. A intolerância é fruto certo deste posicionamento. Em nome de Deus e de sua Palavra, a Bíblia, os fundamentalistas embasam a violência contra os seus adversários, sejam os de dentro ou os de fora. Identificam-se também com o verdadeiro cristianismo, enraizado na vida de Jesus e, mais ainda, nos ensinamentos do apóstolo Paulo. Isto porque "Paulo é o fundador da 'ortodoxia dogmática', ao passo que Jesus nos deixou legado da 'memória subversiva"' (CASTILLO, 2017, p. 122).

Os Fundamentos foram traduzidos para o português tendo uma versão recente impressa em 2005, pela Editora Hagnos: "Os Fundamentos: a famosa coletânea de textos das verdades bíblicas fundamentais", editado por R. A. Torrey; atualizado por Charles L. Feinberg e outros. As suas ideias fazem a cabeça de grande parte do protestantismo de missão e do pentecostalismo no Brasil. O reflexo disso é percebido nos âmbitos da política, da sociedade e da economia. A próxima 
etapa da nossa reflexão consiste em avaliar criticamente a influência e os impactos do fundamentalismo religioso no Brasil de hoje.

\section{Fundamentalismo à brasileira}

O Brasil é um país rico e diverso. A sua história é marcada por empreendimentos colonialistas, mas também pelo intenso intercâmbio entre povos e culturas propiciando à cultura brasileira uma pluralidade sem igual. A diversidade brasileira está presente na língua, nos costumes, nas culturas, na culinária, na religião, apesar da hegemonia do cristianismo, e nos saberes. A grande dimensão geográfica do país possibilita o acolhimento desta alteridade que advém dos espaços fronteiriços, um entre lugar aberto à heterogeneidade.

No que diz respeito ao cristianismo, especificamente o protestantismo, a diversidade também se faz presente. Não é tarefa simples mapear o protestantismo brasileiro. No decorrer da história, o protestantismo brasileiro se multiplicou em inúmeros grupos e denominações. São tantos e diversos que confundem os próprios especialistas empenhados em discernir quem é quem neste complexo pluriverso protestante. "Evangélicos”, “crentes”, “protestantes”, “pentecostais” e "neopentecostais" são alguns dos nomes utilizados, às vezes como sinônimos, por pessoas leigas no assunto referente ao ramo do cristianismo diferente do catolicismo. Por exemplo, as linhas doutrinárias que diferenciavam "protestantes" - batistas, presbiterianos, metodistas etc. - de "evangélicos" - pentecostais e neopentecostais - se romperam com a pentecostalização ou renovação das Igrejas históricas. Como o outro ramo possível da tradição cristã, o das Igrejas ortodoxas, é menos conhecido no Brasil, fica subentendido que o cristianismo no país ou é católico ou é protestante/evangélico.

Não faltam esforços para distinguir as tradições e as teologias por trás do “protestantismo à brasileira”, isto é, ao modo todo específico de ressignificar os princípios da Reforma protestante em terras tupiniquins. ${ }^{4}$ Dentre os empenhos, há

\footnotetext{
${ }^{4}$ Os seguintes textos cooperam para a compreensão do protestantismo brasileiro: (BONINO, 2002|); (LEONARD, 2002); (LONGUINI NETO, 2002); (ZWETSCH, 2008).
} 
a categorização utilizada por Antônio Gouvêa Mendonça e Prócoro Velasques Filho no texto referência Introdução ao protestantismo no Brasil. A pesquisa realizada por Mendonça e Velasques Filho aponta para três grandes eixos do protestantismo brasileiro: Protestantismo de imigração, Protestantismo de missão e Pentecostalismo. Tal classificação, mesmo que com limitações, ajuda a entender como o fundamentalismo entra no Brasil e como ele se configura nas diversas denominações (MENDONÇA; VELASQUES FILHO, 2002, p. 25).

Não nos deteremos no Protestantismo de imigração, o que veio direto da Europa para o Brasil, via imigração, e que a Igreja Evangélica de Confissão Luterana do Brasil (IECLB) é a sua maior representante. Por questões óbvias, o fundamentalismo não veio de carona no Protestantismo de imigração, mas sim, no Protestantismo de origem missionária e no Pentecostalismo. Ambas se utilizaram de agências paraeclesiásticas para difundir o ideal fundamentalista no cenário protestante brasileiro. "Paraeclesiáticas" são organizações missionárias, independentes das grandes Igrejas estadunidenses, que se mantêm graças às contribuições de fiéis comprometidos em sustentar as missões e os seus missionários. São conhecidas como "missões de fé" e agem em três diferentes níveis: evangelização de massa, acampamentos para juventude e literatura (MENDONÇA; VELASQUES FILHO, 2002, p. 56-57). De origem estrangeira, as paraeclesiásticas enfraquecem as Igrejas quando:

[...] Impedem-nas de reformular seu pensamento e prática bem como de avançar, aos poucos, na direção dos valores da sociedade brasileira. $\mathrm{O}$ efeito paralisante atinge duplo objetivo: primeiro, contorna o perigo das Igrejas caminharem para uma teologia mais autônoma que as capacite e as libere para as lutas sociais; segundo, limita a migração dos protestantes tradicionais de origem missionária para as Igrejas pentecostais, Igrejas que, embora portadoras de uma teologia muito conservadora e fundamentalista, situam-se fora de qualquer forma de controle externo (MENDONÇA; VELASQUES FILHO, 2002, p. 24).

No universo protestante brasileiro, o protestantismo de missão engloba Igrejas Congregacionais, Presbiterianas, Metodistas, Batistas, Episcopal e outras comunidades reformadas. Já o pentecostalismo brasileiro, mesmo com a marca da contemporaneidade dos dons (cura, glossolalia e exorcismo), que lhe é constitutiva, 
nasceu de uma iniciativa missionária também. Igrejas como a Congregação Cristã do Brasil, Assembleia de Deus, do Evangelho Quadrangular, o Brasil para Cristo e as inúmeras "Agências de cura divina” compõem o pentecostalismo clássico no Brasil. Mesmo com tanta diversidade de denominações, será que há um elemento em comum que identifique estes grupos com o fundamentalismo religioso? Para Mendonça e Velasques Filho, sim. O que é? O individualismo conversionista e sua ética excludente que, somado à primazia dada a Bíblia, molda a fé e a prática desse ramo do protestantismo brasileiro (MENDONÇA; VELASQUES FILHO, 2002, p. 33).

A influência do fundamentalismo gera efeitos negativos sobre o protestantismo evangélico. José Miguez Bonino faz uma lista destes efeitos: a) Transmissão dos piores traços da ideologia e da política dos Estados Unidos, ao ponto de assumir como próprias campanhas ideológicas reacionárias, regimes de segurança e políticas repressivas da direita religiosa estadunidense; b) no âmbito da ética, legalismo, dualismos, como coisas do mundo e da Igreja, e um falso moralismo; c) no âmbito eclesial, divisionismo e posturas exclusivistas. Bonino ainda continua assinalando para aquilo que ele julga ser o mais grave: distorção doutrinal que legitima e reforça essas tendências. A saber: a) A elaboração de um "plano de salvação" individual a partir de uma lógica de retribuição; b) a transformação da Bíblia em objeto de idolatria - bibliolatria, e c) uma concepção apocalíptica sobre o fim do ser humano e do planeta - concepções milenaristas (BONINO, 2002, p. 46-47).

O impacto negativo do fundamentalismo rompe as fronteiras das Igrejas e avança sobre a sociedade em todas as suas instâncias. Segundo o último Censo Religioso (2010) feito pelo Instituto Brasileiro de Geografia e Estatística (IBGE), dos mais de 42,3 milhões de evangélicos, 60\% são de origem pentecostal. O pentecostalismo é o grupo religioso que mais cresce no Brasil. Ainda segundo o Censo, os "evangélicos de missão" representam 18,5\% e os "evangélicos não determinados” são 21,8\%. Portanto, temos no Brasil um mundo evangélico de expressão quantitativa e com um perfil fundamentalista. O que o Censo não 
identifica com precisão e que precisamos deixar claro é que, neste mundo evangélico, há pequenas comunidades cristãs, evangélicas, entre o protestantismo de missão e o pentecostalismo que não compactuam com as bandeiras do fundamentalismo. Pelo contrário, são grupos minoritários, de teologias progressistas, plurais e inclusivas.

Na instância política, sem ir muito para o passado, mas tendo os últimos cinquenta anos como parâmetro, o protestantismo fundamentalista brasileiro, a partir de 1970, mudou o discurso de que "crente fiel não se mete em política" por outro: "crente se mete em política, sim, desde que seja pela direita". Ao assumir um posicionamento político direitista, na maioria das vezes movido pelo pragmatismo clientelista, troca de favores, e por um anticomunismo, o fundamentalismo vem, no decorrer dos anos, almejando cargos políticos e posições privilegiadas para efetivar a sua agenda em nome da bandeira: "Feliz é a nação cujo Deus é o Senhor" (Sl 33,12). A participação de evangélicos fundamentalistas vai se tornando cada vez mais ativa e articulada. Candidatos "oficiais das Igrejas" são lançados por denominações e eleitos com a participação eficaz dos fiéis. Assim, no presente, o Congresso Nacional é marcado por uma "bancada evangélica", "que se notabilizaria por seu fisiologismo e sua falta de ética” (CAVALCANTI, 1994, p. 233).

Os evangélicos fundamentalistas vêm crescendo tanto nos últimos anos que têm contribuído para a exacerbação do ultraconservadorismo na sociedade brasileira. O cenário político da atualidade é tomado por posicionamentos fundamentalistas que afetam toda à sociedade. Com um discurso agressivo e, ao mesmo tempo, baseado em um tipo de leitura dos textos bíblicos, políticospastores, políticas-pastoras e lideranças fundamentalistas mostram que os avanços sociais são negativos e perversos. Por exemplo, muitos fiéis desses grupos, em nome da moral cristã e dos princípios bíblicos, decidiram parar de enviar seus filhos para a escola devido à educação em prol da inclusão. Passaram, inclusive, a denunciar o que classificam de propagação da "ideologia de gênero" por parte do governo (FRENTE PARLAMENTAR EVANGÉLICA, 2018). 
No Brasil, os evangélicos fundamentalistas, pentecostais ou do protestantismo de missão, são a principal base eleitoral do presidente Jair Messias Bolsonaro, aponta a pesquisa realizada pela Datafolha em 2020 (BÄCHTOLD, 2020). Além disto, ocupam cargos importantes no governo bolsonarista. O mesmo pode ser dito sobre o governo dos Estados Unidos de Donald Trump. Para o historiador americano Andrew Chestnut, em entrevista à BBC News Brasil, “a coesão ideológica dos evangélicos”, facilitando articulações políticas e “a capacidade de ecoar pensamentos compartilhados por setores conservadores da classe média e alta" são alguns dos fatores que contribuem para o avanço de políticas fundamentalistas. Para Chestnut, o principal temor relacionado ao aumento da ingerência evangélica fundamentalista na política "é o de que líderes eleitos com o apoio desses setores acabem aprovando políticas públicas que, na prática, discriminem outros credos religiosos ou que signifiquem retrocessos na conquista de minorias" (PASSARINHO, 2019).

O temor do professor americano é uma realidade no Brasil. Igrejas e líderes evangélicos fundamentalistas enaltecem figuras autoritárias e suas iniciativas (BÄCHTOLD, 2020). Há empatia com ações que reforçam discriminação e intolerância. Apoio ao Estado de Israel e o sionismo cristão, rejeição da comunidade LGBTQ+, antifeminismo, combate às religiões afro, conversão dos índios, alienação ambiental, exclusão racial e educação pautada na Bíblia são alguns dos posicionamentos de um governo que pensa e age absorvido por uma mentalidade fundamentalista. Quando a violência à diversidade e à pluralidade "se reveste de roupagem religiosa, acende o alarme de que se choca o ovo da serpente. O nazismo resultou também da perversa ideologia religioso que acusa os judeus de 'assassinos de Cristo”, lembra frei Betto (BETTO, 2019, p. 54).

Vivemos um momento delicado no Brasil. A impressão que se tem é que avanços sociais conquistados nos últimos governos, mesmo que imperfeitos, estão perdendo força diante da redução mínima do Estado e do enaltecimento do mercado financeiro. Nesta luta, o fundamentalismo evangélico brasileiro faz uma opção pelo opressor e, com ele, legitima políticas que empobrecem, marginalizam e 
subalternizam os mais fracos. Numa espécie de docetismo moderno, evangélicos fundamentalistas esvaziam a humanidade de Jesus Cristo e o apresentam ao mundo como um ser plenamente divino, intocável e inabalável. Ora, a lógica dos Evangelhos, de onde vem "evangélico", não é essa. Não nos aproximamos do Deus de Jesus divinizando-nos, mas humanizando-nos. A representação equivocada de Deus e do seu Filho desumaniza. Deus desceu à condição de criatura a tal ponto, que é uma criatura que nos mostra presente o ser mesmo de Deus. O homem Jesus de Nazaré revelou em sua humanidade tal grandeza e profundidade que os seus discípulos, depois de um longo processo de reconhecimento, constataram: "humano assim como Jesus só pode ser Deus mesmo" (BOFF, 1986, p. 131). Jesus Cristo humaniza. Já o fundamentalismo não.

\section{Considerações finais}

Ao lado das virtudes teologais fé e caridade, a esperança vê como possível àquilo que deseja. Diferente de aguardar, esperar, de onde vem esperança, implica em uma postura dinâmica, ativa. É preciso fazer algo. Diante da realidade exposta sobre o fundamentalismo à brasileira, precisamos elaborar ações propositivas a fim de evitar o avanço da alienação religiosa no mundo contemporâneo, do discurso do ódio e das ações violentas. Não se trata de apresentar receitas simplistas contra a complexidade do fundamentalismo presente no protestantismo de missão e no pentecostalismo. A ideia aqui é refletir, de modo inconcluso e embrionário, sobre a possibilidade de repensar a formação, e não formatação, teológica de lideranças evangélicas no Brasil.

Vimos que a realidade do pluriverso evangélico no país não é nada animadora. Além do fundamentalismo, a lógica da barganha pregada pelas igrejas de mercado e sucesso criou um tipo de crente disposto a negociar a fé em nome de uma vida abundante de tesouros "onde traça e ferrugem corroem e onde ladrões escavam e roubam" (Mt 6,19). Por outro lado, dentro deste mesmo protestantismo, ressurgem pequenos e ativos grupos liderados por pastores, pastoras e lideranças leigas sensíveis ao mundo e dispostos ao diálogo fraterno e plural. Estes grupos 
estão difusos por todo Brasil, em Igrejas, pastorais, associações, seminários, faculdades de teologia e conselhos ecumênicos. É uma minoria sim, mas gente consciente do seu serviço, da sua vocação. Ouve-se a sua voz das redes sociais aos palanques armados nos espaços públicos. Plantados como pequenas sementes, tais lideranças, grande parte formada por jovens, dão o tom da grande boa nova de Jesus Cristo. 5

Boa parte dessas lideranças veio de denominações ou Igrejas fundamentalistas. Só foram ter consciência da teologia fundamentalista que professavam e praticavam quando interpelados por um labor teológico crítico. Alguém com paciência e dedicação orientou, ou numa linguagem evangélica "pastoreou”, essas pessoas rumo à inteligência da fé lúcida e marcada por boas obras. ${ }^{6}$ Não se combate o fundamentalismo sendo fundamentalista. É preciso discernimento. Pequenas iniciativas de acolhimento e transparência teológica têm surgido efeito na vida de muitos evangélicos no Brasil. O trabalho feito pelas faculdades de teologia, fraternidades teológicas, organismos ecumênicos e de diálogo inter-religioso, editoras empenhadas na publicação de teologia brasileira e iniciativas de pequenas comunidades de fé assinalam um caminho de esperança para um protestantismo brasileiro maduro, participativo nas causas do mundo e, sobretudo, livre do fundamentalismo.

Nesta caminhada é importante reforçar a importância da unidade na diversidade. O problema não é o conservadorismo, mas o fundamentalismo. Historicamente, o protestantismo sempre acolheu a diversidade, apesar dos conflitos. Não se pode esmorecer agora. A tolerância é necessária. A divergência de pensamento faz parte do diálogo maduro e respeitoso.7 Nesta relação, precisamos

\footnotetext{
${ }^{5}$ Citamos aqui alguns grupos comprometidos com o diálogo ecumênico: Conselho Latino-Americano de Igrejas (CLAI), Conselho Nacional de Igrejas Cristãs do Brasil (CONIC), Aliança Bíblica Universitária (ABU), Fraternidade Teológica Latino-Americana (FTL), Coordenadoria Ecumênica de Serviços (CESE), Jornadas Ecumênicas: KOINONIA Presença Ecumênica e Serviço, Rede Ecumênica da Juventude (REJU) e outros.

${ }^{6} \mathrm{~A}$ história de liderança de dois importantes pastores brasileiros reforçam a ideia da importância de uma formação teológica contextual e crítica: Ariovaldo Ramos e Ed René Kivitz. O mesmo se aplica para muitos outros pastores, outras pastoras e lideranças. (BRANDINO, 2020; VASCONCELOS, 2020).

${ }^{7}$ Jürgem Moltmann sugere que o diálogo digno se faz por meio do acolhimento do diferente na relação: “O diálogo deve girar em torno da pergunta pela verdade, mesmo que não seja possível chegar a um consenso em relação a ela. Pois o consenso não é o objetivo do diálogo. Se um dos parceiros for convencido pelo outro, acaba o diálogo. Quando dois dizem a mesma coisa, um deles está sobrando [...]" (MOLTMANN, 2004, p.28-29).
} 
separar o que é fundamental do não essencial. Há ideias e práticas que geram discussões desnecessárias e ações inofensivas. O problema mais sério reside na absolutização de um pensamento como verdade absoluta, impô-lo sobre as pessoas e combater com violência os diferentes. Perde-se muito tempo com questões

periféricas deixando de lado as essenciais. Avancemos no diálogo digno, fraterno e refutemos as premissas fundamentalistas com inteligência e, sobretudo, com ações genuinamente cristãs.

\section{REFERÊNCIAS}

"BRASIL ACIMA DE TUDO": conheça a origem do slogan de Bolsonaro, Gazeta do Povo, 24 out. 2018. Disponível em:

https://www.gazetadopovo.com.br/politica/republica/eleicoes-2018/brasil-acima-detudo-conheca-a-origem-do-slogan-de-bolsonaro-7r6utek3uk1axzyruk1fj9nas/. Acesso em: 27 maio 2020.

ALMOND, Gabriel A.; SIVAN, Emmanuel; APPLEBY, R. Scott. Fundamentalisms genus and species. In: MARTY, Martin E.; APPLEBY, R. Scott. Fundamentalisms comprehended. Chicago and London: The University of Chicago Press, 1991. (The Fundamentalism Project, v. 5).

ARENS, Eduardo. A bíblia sem mitos: uma introdução crítica. 3. ed. rev. aum. São Paulo: Paulus, 2007.

BÄCHTOLD, Felipe. Evangélicos têm tendência pró-Bolsonaro e relativizam mais coronavírus, indica Datafolha. Folha de S. Paulo, São Paulo, 2020. Disponível em: https://www1.folha.uol.com.br/poder/2020/o4/evangelicos-tem-tendencia-probolsonaro-e-relativizam-mais-coronavirus-indica-datafolha.shtml. Acesso em: 18 de fev. de 2021.

BARR, James. Fundamentalism. London: SCM, 1977.

BETTO, Frei. Fé e afeto: espiritualidade em tempos de crise. Petrópolis: Vozes, 2019.

BÍBLIA de Estudo Almeida. São Paulo: Sociedade Bíblica do Brasil, 1999.

BOFF, Leonardo. Jesus Cristo libertador. 18. ed. Petrópolis: Vozes, 1986.

BONINO, José Miguez. Rostos do protestantismo latino-americano. São Leopoldo: Sinodal, 2002.

BRANDINO, Géssica. Evangélicos críticos de Bolsonaro criam bancada alternativa por candidaturas progressistas. Folha de S. Paulo, São Paulo, 2020. Disponível em: <https://www1.folha.uol.com.br/poder/2020/o8/criticos-de-bolsonaro-evangelicoscriam-bancada-alternativa-por-candidaturas-progressistas.shtml>. Acesso em: 19 fev. 2021. 
CARPENTER, Joel A. Fundamentalist institutions and the rise of evangelical protestantism, 1929-1942. In: MARTY, Martin E. (ed.) Modern american protestantism and its world: fundamentalism and evagelicalism. Munich: K. G. Saur, 1993.

CASTILlO, José M. A humanidade de Jesus. Petrópolis: Vozes, 2017.

CAVALCANTI, Cavalcanti. Cristianismo e política: teoria bíblica e prática histórica. 3 . ed. amp. São Paulo: Temática Publicações, 1994.

CUNHA, Carlos. Hermenêutica bíblica libertadora: encontro entre católicos e pentecostais. São Paulo: Garimpo, 2016.

DA REDAÇÃO. “A Bíblia volta ao palácio”, diz recém-empossada presidente da Bolívia. Veja, 13 nov. 2019. Disponível em: https://veja.abril.com.br/mundo/a-biblia-volta-aopalacio-diz-recem-empossada-presidente-da-bolivia/. Acesso em: 27 maio 2020.

DOBSON, E.; FALWELL, J.; HINDSON, E. E. The fundamentalist phenomenon: the resurgence of conservative Christianity. 2. ed. Ada, Michigan: Baker Publishing Group, 1986.

DREHER, Martin N. Fundamentalismo. In: BORTOLLETO FILHO, Fernando. (org.). Dicionário brasileiro de teologia. São Paulo: Aste, 2008.

FIORI, Marcus Fernando; NENEVÊ, Miguel. Dogmatismo, alienação e miséria cultural: uma reflexão sobre o julgamento do macaco Scopes. Revista Pesquisa \& Criação, Porto Velho, v. 10, n. 2, p. 49-57, jul.-dez. 2011.

FRENTE PARLAMENTAR EVANGÉLICA pede fim da ideologia de gênero nas escolas, Gazeta do Povo, 8 nov. 2018. Disponível em:

https://www.gazetadopovo.com.br/educacao/frente-parlamentar-evangelica-pede-fim-daideologia-de-genero-nas-escolas. Acesso em: 27 maio 2020.

GEISLER, Norman; NIX, William. Introdução bíblica: como a Bíblia chegou até nós. São Paulo: Editora Vida, 1997.

GRENZ, Stanley J.; GURETZKI, David; NORDLING, Cherith Fee. Dicionário de teologia. São Paulo: Editora Vida, 2000.

HANKINS, Barry (ed.). Evangelicalism and fundamentalism: a documentary reader. New York University Press, 2008.

IBGE, Censo religioso do Brasil 2010. Disponível em: https://ibge.gov.br/brasil/. Acesso em: 20 maio 2020.

LEONARD, Emile G. O protestantismo brasileiro: estudo de eclesiologia e história social. 3. ed. Rio de Janeiro: JUERP; São Paulo: ASTE, 2002. 
LONGUINI NETO, Luiz Longuini. O novo rosto da missão: os movimentos ecumênicos e evangelical no protestantismo latino-americano. Viçosa: Ultimato, 2002.

MARSDEN, George M. Fundamentalism and american culture: the shaping of twentiethcentury evangelicalism 1870-1925. Oxford: Oxford University Press, 1980.

MARSDEN, George M. Understanting fundamentalism and evangelicalism. Michigan:

William B. Eerdmans Publishing Company, 1991.

MARTIN, William. With God our side: the rise of the religious right in America. New York: Bradway Books, 1996.

MARTY, Martin E. Fundamentalismo. In: LACOSTE, Jean-Yves. Dicionário crítico de teologia. São Paulo: Paulinas: Edições Loyola, 2004.

MCINTIRE, C.T. Fundamentalismo. In: ELWELL, Walter A. (ed.). Enciclopédia histórico-teológica da igreja cristã. São Paulo: Edições Vida Nova, 1990. v. 2.

MENDONÇA, Antônio Gouvêa; VELASQUES FILHO, Prócoro. Introdução ao protestantismo no Brasil. 2. ed. São Paulo: Edições Loyola, 2002.

MOLTMANN, Jürgen. Experiências de reflexão teológica: caminhos e formas da teologia cristã. São Leopoldo: Unisinos, 2004.

MOLTMANN, Jürgen. Fundamentalismo e modernidade. Concilium, Petrópolis, n. 241, p. 141-148, 1993.

NOLAN, Albert. Jesus hoje: uma espiritualidade de liberdade radical. São Paulo: Paulinas, 2008.

OZ, Amós. Contra o fanatismo. 2. ed. Rio de Janeiro: Ediouro, 2004.

PACE, Enzo; STEFANI, Piero. Fundamentalismo religioso contemporâneo. São Paulo: Paulus, 2002.

PASSARINHO, Nathalia. Por que igrejas evangélicas ganharam tanto peso na política da América Latina? Especialista aponta 5 fatores. BBC News, 22 nov. 2019. Disponível em: https://www.msn.com/pt-br/noticias/mundo/como-igrejas-ganharaminflu\%C3\%AAncia-na-pol\%C3\%ADtica-latina. Acesso em: 27 maio 2020.

PIERUCCI, Antônio Flávio. Fundamentalismo e integrismo: os nomes e a coisa. Revista USP, São Paulo, n. 13, p. 144-156, maio 1992.

SILVA, I. D.; BARBOSA, W. V. Religião e política nos EUA: Jerry Falwell e a presença do fundamentalismo evangélico no espaço público americano. Curitiba: Appris, 2019.

UOL Eleições 2018. Bolsonaro cita Bíblia e diz que faz campanha simples, sem "milhões" do PT, 14 out. 2018. Disponível em:

https://noticias.uol.com.br/politica/eleicoes/2018/noticias/2018/10/14/bolsonaro-citabiblia-e-diz-que-faz-campanha-simples-sem-milhoes-do-pt.htm. Acesso em: 27 maio 2020. 
VASCONCELOS, Mônica. Visões diferentes de Deus são origem de cisão entre evangélicos conservadores e progressistas no Brasil, diz pastor Ed Kivitz. BBC News, 17 dez. 2020. Disponível em: https://www.bbc.com/portuguese/brasil-55320830. Acesso em: 19 fev. 2021.

ZWETSCH, Roberto E. Missão como com-paixão: por uma teologia da missão em perspectiva latino-americana. São Leopoldo: Sinodal; Quito: CLAI, 2008. 